TECHNO

Vol.21, No.2, Oktober 2020, Hal. 125 130

\title{
Analisis Media Sosial Facebook Lite dengan tools Forensik menggunakan Metode NIST
}

\author{
Rauhulloh Ayatulloh Khomeini Noor Bintang ${ }^{1}$, Rusydi Umar ${ }^{2}$, Anton Yudhana ${ }^{3}$ \\ ${ }^{1}$ Program Studi Sistem Informasi, Universitas Ahmad Dahlan \\ ${ }^{2}$ Program Studi Sistem Informasi, Universitas Ahmad Dahlan \\ ${ }^{3}$ Program Studi Teknik Elektro, Universitas Ahmad Dahlan
}

\begin{tabular}{|c|c|}
\hline Informasi Makalah & INTISARI \\
\hline $\begin{array}{l}\text { Dikirim, } 29 \text { Agustus } 2020 \\
\text { Direvisi, } \\
\text { Diterima, }\end{array}$ & $\begin{array}{l}\text { Media Sosial menjadi sangat popular dikalangan masyarakat sekarang ini, dan } \\
\text { meningkatnya jumlah penggunaan media sosial tentu saja membawa dampak } \\
\text { baik maupun dampak buruk terhadap berlangsungnya perjalanan kehidupan } \\
\text { manusia, contoh dari dampak buruk yaitu melakukan pencemaran nama baik } \\
\text { atau melakukan penipuan pada media sosial. Ilmu pada Forensik digital yaitu } \\
\text { cara untuk menangkap pelaku kejahatan pada digital yang akan diperlukan }\end{array}$ \\
\hline & $\begin{array}{l}\text { pada barang bukti dalam persidangan. Para pelaku kejahatan media sosial } \\
\text { membutuhkan Smartphone untuk melakukan kejahatan dalam digital. Pada }\end{array}$ \\
\hline Forensic Digital & penelitian ini akan mengangkat barang bukti kejahatan digital pada aplikasi \\
\hline $\begin{array}{l}\text { Media Sosial } \\
\text { NIST }\end{array}$ & $\begin{array}{l}\text { facebook lite menggunakan forensik. Pada penelitian ini tool forensik yang } \\
\text { akan digunakan yaitu tools forensik MOBILEedit Forensik Pro dengan }\end{array}$ \\
\hline Mobile Forensic & $\begin{array}{l}\text { bantuan menggunakan metode National Institute Of Standars Techlogogy } \\
\text { (NIST). NIST memiliki alur kerja yang baik untuk melakukan ekstraksi data }\end{array}$ \\
\hline & $\begin{array}{l}\text { digital forensik. Hasil penelitian akan didapatkan berupa Akun yang } \\
\text { digunakan, Audio, Conversations, dan Images. }\end{array}$ \\
\hline
\end{tabular}

Keyword:

Digital Forensic

Social Media

NIST

Mobile Forensic

\begin{abstract}
Social Media is becoming very popular among the public today, and the increasing number of social media use has of course a good or bad impact on the course of human life, for example the bad impact is doing cyberbully or chating on social media. Digital forensics is one of the sciences for how to catch criminals in digital which will be needed in evidence in court. Social media criminals need Smartphones to commit digital cybercrime. This research will raise evidence of digital crimes on the Facebook Lite application using forensics. In this study, the forensic tool that will be used is the MOBILEedit Forensic Pro forensic tools with the help of using methods NIST National Institute Of Standars Techlogogy. NIST has a good workflow for extracting digital forensic data. The research results will be obtained in the form of accounts Id, audio, conversations, and images.
\end{abstract}

\section{Korespondensi Penulis:}

Rauhulloh Ayatulloh Khomeini Noor Bintang

Magister Teknik Informatika

Universitas Ahmad Dahlan Yogyakarta

Jalan. Prof DR Soepomo, Warungboto, Umbulharjo,

Kota Yogyakarta, Daerah Istimewa Yogyakarta 55164

Email: rahullbintang5@gmail.com

\section{PENDAHULUAN}

Salah satu jejaring sosial media paling popular pada kalangan masyarakat adalah Facebook. Bertambahnya jumlah pada pengguna Facebook tentu saja membawa dampak baik maupun dampak buruk 
yang di terima oleh masyarakat salah satu contoh dampak buruk terhadap masyarakat yaitu menggunakan media sosial dengan cara melakukan tindakan kejahatan pada media sosial contohnya penipuan jual beli online maupun Cyberbully atau tindakan merendahkan derajat orang lain. Pada kejehatan digital yang dapat dilakukan melalui platform media sosial Facebook Lite dengan bertujuan untuk kriminal kejahatan dengan melakukan penipuan jual beli online, melakukan kegiatan perdagangan narkoba, melakukan jual beli PSK online maupun melakukan tindakan kriminal lainnya. Dalam kejahatan diatas berikut pasti aka nada yang Namanya barang bukti digital dan pasti meningggalkan jejak-jejak barang bukti digital, barang bukti digital berikut dapat digunakan untuk sebagai laporan tindak kejahatan media digital di pengadilan nanti.

Komputer Forensik yaitu melakukan investigasi dan menggunakan Teknik analis pada computer yang memerlukan tahapan identifikasi, persiapan, ekstraksi, dokumentasi dan interpretasi dari suatu data yang ada pada suatu perangkat komputer. Tindak kejahatan yang dilakukan pada media sosial penggunanya dapat diketahui melalui dari analisis data Volatile yang terdapat pada RAM [1]. Perangkat Selular semakin lama akan menggantikan peran dari sebuah komputer, fitur yang digunakan pada Smartphone mempunyai aplikasi yang semakin canggih mengikuti perkembangan era digital pada saat ini, Smartphone pada era saat ini banyak mengambil dari teknologi yang ada pada komputer PC terutama dalam hal media penyimanan storage, dalam hal penyimanan pada data Smartphone saat ini memberikan kapasitas penyimpanan besar untuk digunakan sebagai media penyimpanan data [2].

Pada pertumbuhan angka pengggunaan media sosial dan pesan instan pada aplikasi lainnya telah memfasilitasi perkembangan digital kejahatan Cyber dan aktifitas-aktifitas kejahatan yang sangat serius, banyaknya penyedia pesan instan dan banyaknya macam-macam media sosial yang telah memperluas jangkauan layanan ke dalam jenis-jenis platform empiris [3]. Pada teknologi Smartphone pertahun semakin polular, salah satunya teknologi dengan jumlah terbanyak yaitu teknologi jenis handphone Smartphone dengan menggunakan android sebagai system operasinya. Smartphone android cukup bersaing dalam pasar jenis Smartphone dan penggunaan jumlah Smartphone mempengaruhi pengembangan maupun fitur dalam Smartphone itu sendiri terutama dalam aplikasi Mobile, termasuk aplikasi install facebook [3]. Dalam model penerapan analisis penyidik memerlukan barang bukti digital asli, penyidik bekerja dengan menggunakan bukti fisik dengan contoh yaitu penyimpanan data pada internat perangkat komputasi tertentu [4]. Pemilihan pada suatu Metode Penelitian, Investigasi, dan Model yang digunakan secara sistematika pada forensik digital pada dasarnya harus menggunakan tahapan individulitas, mengulangan, kehandalan, kinerja yang digunakan, kemampuan uji yang di pakai, dan standard kualitas atau mutu standard yang digunakan. Pada analisa forensik yang akan digunakan menurut kualiatas standard dapat mengacu pada metode yang dapat digunakan dari NIJ National Institute of Justice melalui tahapan kerja Identification, Collection, Examination, Analysis, dan Reporting. Dapat juga menggunakan salah satu metode dari NIST National Institute of Standard and Technology dengan melakukan alur kerja Collection, Examination, Analysis, dan Reporting [5].

\section{METODE}

Yang digunakan pada penelitian berikut ini menggunakan adaptasi dan melakukan tahapan pada metode analisa forensik NIST National Institute of Standard and Technology. Metode berikut menjelaskan bagaimana alur tahapan penelitian sehingga dapat dilakukan suatu langkah penelitian secara terstruktur agar dapat digunakan untuk pedoman dalam menyeselesaikan suatu persoalan yang ada [6]. Pada metode berikut terdapat berbagai tahapan forensik yang dapat dilihat pada gambar 1 .

\section{Bollegtion}

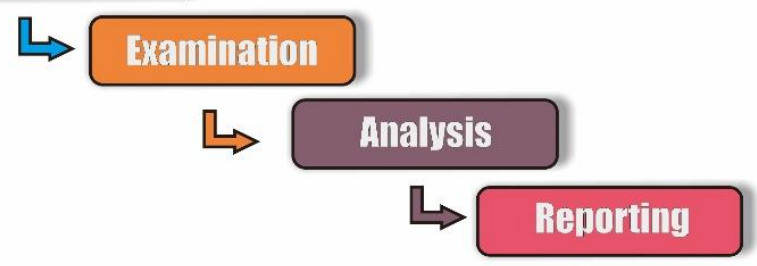

Gambar 1. Alur Metode NIST

Techno Vol. 21, No. 2, Oktober 2020: $125-130$ 
Penjelasan pada alur National Institute of Standards and Technology (NIST), yaitu Collection, Examination, Analysis, dan Reporting sebagai berikut.

1. Collection

Tahapan ini merupakan tahapan yang mengumpulkan, mengidentifikasi, memberi label, merekam, dan mengambil dana dari sumber data dengan menggunakan perangkat Smartphone dengan menjada integritas data.

\section{Examination}

Tahapan ini merupakan tahapan melakukan pemeriksaan pengolahan data yang telah didapatkan secara forensik baik dilakukan dengan cara otomatis maupun manual data yang sesuatu kebutuhan digital forensik dengan tetap menjaga integritas data.

3. Analysis

Tahapan ini merupakan tahapan analisis dengan melakukan hasil dari pemeriksaan data digital forensik dengan menggunakan metode yang secara hukum benar dan memperoleh informasi yang berguna untuk kepentingan penyidik dan dapat dipertanggung jawabkan.

4. Reporting

Tahapan ini merupakan tahapan pelaporan pada hasil yang sudah di dapatkan didalam analisis itu, termasuk mendeskripsi penelitian yang sudah dilakukan, menjelaskan tools forensik yang digunakan, serangkaian tahapan yang dipilih, lalu menentukan tindakan berikutnya yang wajib dilakukan. Dan memberi saran maupun rekomendasi pada penelitian akhir agar dapat memperbaiki prosedur, tools forensik, kebijakan, dan aspekaspek forensik lainnya.

\subsection{Simulasi Pada Sistem Perancangan Penelitian}

Simulasi pada sistem perancangan untuk memperoleh hasil bukti digital agar dapat dilakukan tahapan analis digital forensik. Gambar 2 menunjukan bagaimana tentang rancangan yang akan dilakukan guna untuk mendapatkan hasil dari penelitian.

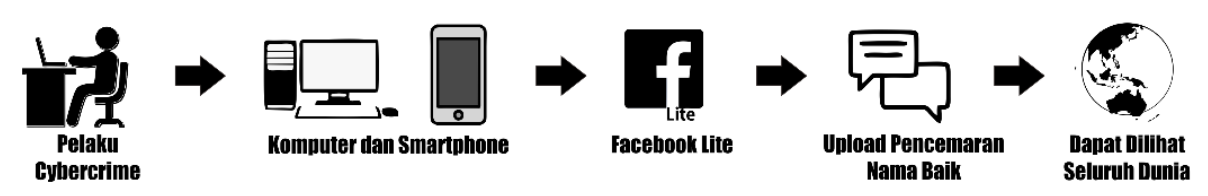

Gambar 2. Tahapan Analisis

Gambar 2 menggunakan skenario tahapan analisis yang digunakan terhadap aplikasi media sosial facebook lite dimana pada tahapan akhir didapatkan hasil data yang dikeluarkan melalui softwate MOBILedit Forensik. Analilis pada perangkat komputer menggunakan perangkat komputer dibutuhkan sebuah metode penelitian yang akan digunakan, guna membantu menemukan barang bukti digital untuk di investigasi forensik. Pada tahapan awal dalam penelitian ini dengan membuat akun pada aplikasi Facebook Lite dan membuat postingan ujaran kebencian pada media sosial facebook lite. Pada tahap alat forensik yang akan digunakan pada penelitian ini yaitu menggunakan alat forensik MOBILedit Forensik yang berguna mengekstrak data dari sebuah Smartphone yang akan dianalisis. Dan untuk mencari akun media sosial facebook lite dilakukan dengan cara mengCloning data agar data tersebut menjadi nilai string asti atau data asli. Pada tahapan selanjutnya yaitu akun media sosial berikut akan dianalisis sesuah prosedur yang dimiliki tahapan forensik agar mendapatkan validasi data forensik yan utuh. Selanjutnya tahapan akhir pada penelitian yaitu tahapan Reporting atau melaporkan hasil dari penelitian mengenai pada aplikasi media sosial yang telah digunakan berupa barang bukti digital yang sudah valid tersebut, yang akan dilakukan pada tahapan Reporting pula menjelaskan tahapantahapan proses yang telah digunakan agar memperoleh barang bukti digital yang diperlukan tersebut terbukti Asli dan Valid. 


\section{HASIL DAN PEMBAHASAN}

Penelitian yang telah dilakukan akan mendapatkan hasil data forensik yang akan dipertanggung jawabkan didalam persidangan pengadilan. Proses yang digunakan untuk mendapatkan barang bukti digital melalui sebuah perangkat Smartphone dengan menggunakan Operasi Sistem Android dan menggunakan alat forensic MOBILedit Forensik. Berikut hasil yang telah didapatkan. Berikut adalah tabel 1 mengenai nama item, spesifikasi dan bahan yang akan digunakan pada penelitian ini.

Tabel 1. Alat dan bahan

\begin{tabular}{cccc}
\hline Nomor & Nama Item & Spesifikasi & Keterangan \\
\hline 1. & Komputer & HP 510-p013 & Perangkat Keras \\
\hline 2. & Smartphone & Samsung Galaxy J2 & Perangkat Keras \\
\hline 3. & Facebook Lite & Aplikasi Android & Perangkat Lunak \\
\hline 4. & $\begin{array}{c}\text { MOBILedit Forensic } \\
\text { Express PRO }\end{array}$ & Alat Forensik & Perangkat Lunak \\
\hline
\end{tabular}

\subsection{Collection}

Pada tahap Collection dengan menggunakan perangkat keras Smartphone. Operasi sistem yang digunakan untuk penelitian ini menggunakan android versi lolipop dengan seri 5.1.1. dan model Smartphone yang digunakan yaitu Samsung Galaxy J2 dengan nomor model SM-J200G.

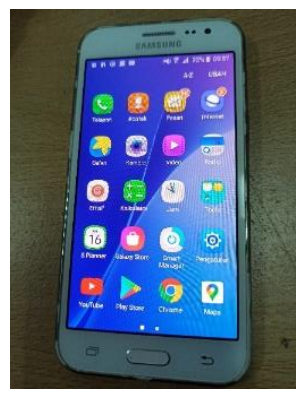

Gambar 3. Smartphone yang digunakan

Pada gambar 3.1 menunjukan Smartphone yang akan digunakan pada penelitian ini. Smartphone yang akan digunakan harus melalui proses Rooting terlebih dahulu. Rooting adalah proses awal dari tahap penelitian pada forensic digital mobile agar akses pada sebuah Smartphone secara total. Pada tahapan Collection melakukan persiapan untuk melakukan ekstrak data dengan menggunakan Smartphone yang telah ditentukan, dan dilanjutkan tahapan Examination.

\subsection{Examination}

Pada proses Examination merupakan pengujian pada software Facebook Lite dengan menggunakan tools forensic yang telah disediakan. Tahapan Examination mengekstraksi data dan imaging data yang dilakukan pada sistem yang menggunakan alat tools forensic. Pada penelitian ini menggunakan alat tools forensic MOBILEdit Forensic pada gambar 3.2 menunjukan proses Examination menggunakan alat bantu tools forensic MOBILedit Forensic Pro.

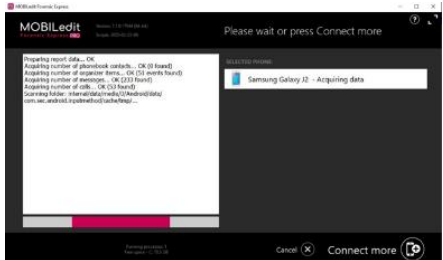

Gambar 4. Examination tools Forensic

Berikutnya setelah dilakukan proses imaging yang dilakukan tersebut akan menghasilkan sebuah file atau full Report dalam bentuk file HTML seperti pada gambar 3.3. pada gambar 3.3 merupakan data yang telah 
ditemukan pada aplikasi media sosial Facebook Lite dengan menggunakan Smartphone jenis Samsung Galaxy $\mathrm{J} 2$.

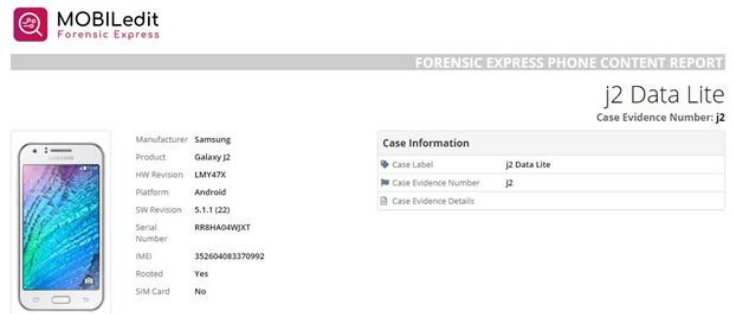

Gambar 3.3

\subsection{Analysis}

Pada Proses analysis berikut akan ditemukan beberapa barang bukti dari Tools MOBILEdit forensic Pro. Berikut masing-masing barang bukti yang telah ditemukan menggunakan tools forensic yang telah digunanakan.

\section{Other Media Files

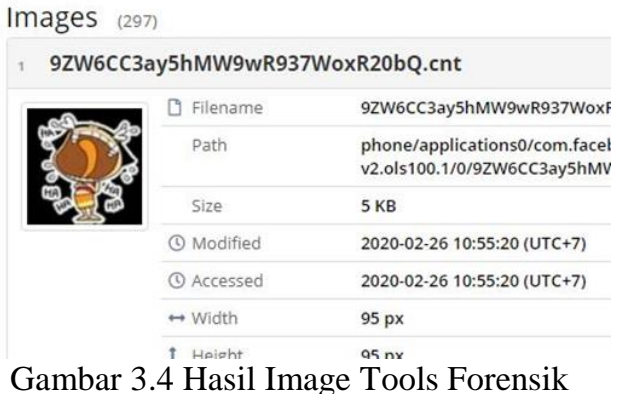

Gambar 3.4 hasil dari ekstraksi data yang dilakukan tools forensic Mobiledit forensic pro dengan menghasilkan ekstraksi data Images sebanyak 297 images dengan masing-masing gambar mempunya sixe, filename, width yang berbeda-beda.

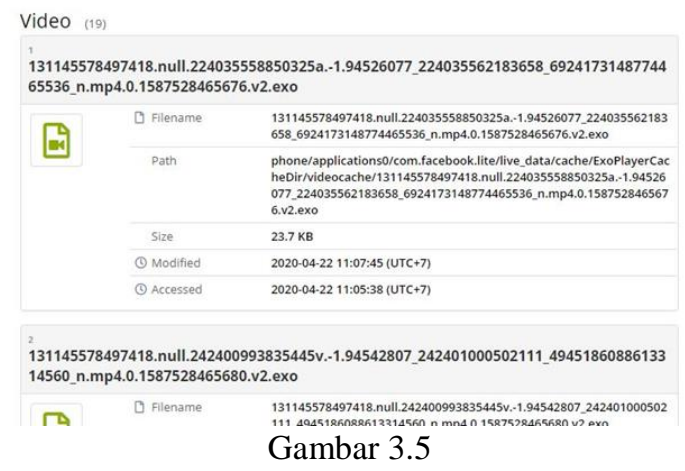

Pada gambar 3.5 hasil dari ekstraksi menggunakan tools forensic di dapatkan hasil Video dengan jumlah 19 jenis Video lalu masing-masing dari jenis filename, path, size, modified yang berbeda-beda.

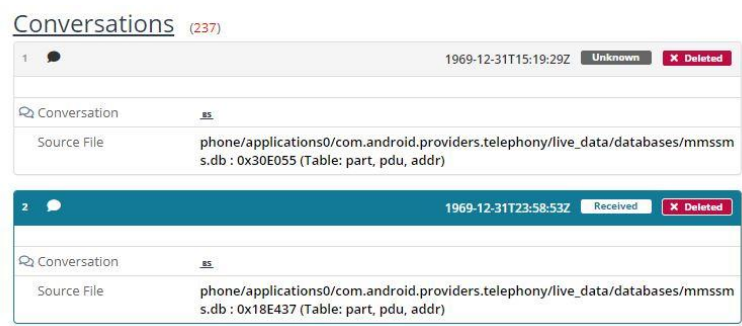

Gambar 3.6

Pada gambar 3.6 dapat ditemukan Jenis File Concersations yang ada pada sebuah Smartphone J2 yang telah dilakukan ekstraksi menggunakan tools forensic Mobiledit Forensic Pro. Pada data tersebut ditemukan masingmasing jenis sebuah percakapan yang telah dilakukan pada Smartphone tersebut. 


\subsection{Reporting}

Pada tahapan Reporting ini menjelaskan tahapan hasil analisis yang selesai pada tahapan analisis, berikut hasil dari tools forensic yang dapat dibuat tabel sebagai berikut.

Tabel 2. Hasil MobilEdit

\begin{tabular}{c|c} 
Parameter yang dicari & Tools Forensic \\
\hline Akun ID & Yes \\
\hline Image & Yes \\
\hline Audio & Yes \\
\hline Video & Yes \\
\hline URL & Not Yet
\end{tabular}

Pada tahap ini dilakukan menggunakan skenario imaging pada sebuah Smartphone dengan menggunakan alat bantu tools forensic MOBILEdit Forensik Pro dan dapat menampilkan berupa Akun Id, Image, Audio, dan Video pada saat menggunakan tools forensik tersebut.

\section{KESIMPULAN}

Berdasarkan hasil dari proses penelitian yang dilakukan telah di dapatkan hasil dari scenario dengan menggunakan Smartphone Android Galaxy J2, dengan melakukan Rooting, dan menginstall aplikasi Facebook Lite, Membuat Postingan, dan melakukan proses investigasi menggunakan tools Forensik yang bernama MOBILedit Forensik, kemudian melakukan analisis menggunakan tools forensic tersebut dan mendapatkan hasil analisis yang akan menjadi barang bukti digital. Hasil yang telah didapatkan dalam penggunaan tools forensic berikut yaitu Akun ID , Image, Audio, Video dengan menggunakan suatu metode National Institute Of Standards Technology (NIST). Saran untuk penelitian lebih lanjut dapat membandingkan metode yang digunakan dan menggunakan alat forensic lainnya.

\section{UCAPAN TERIMAKASIH}

Sekalu sebagai penulis saya menghanturkan rasa terimakasih terhadap segenap rekan-rekan Universitas Ahmad Dahlan Yogyakarta terutama pada rekan Magister Teknik Informatika Universitas Ahmad Dahlan Jogjakarta atas masukan, bimbingan dan supportnya sehingga penulis telah menyelesaikan penelitian ini dengan baik dan benar.

\section{DAFTAR PUSTAKA}

[1] R. Umar, A. yudhana et al., "Analisis Kinerja Metode Live Forensics Untuk Investigasi Random Access Memory Pada Sistem," Prosiding Konferensi Nasional Ke- 4,, SBN: 978-602-19568-1-6 pp. 207-211, 2017.

[2] A. Yudhana, R. Umar et al., "Akuisisi Data Forensik Google Drive Pada Android Dengan Metode National Institute of Justice (NIJ)," 4, No 1 (2018).

[3] N. Anwar, I. Riadi., " Analisis Investigasi Forensik WhatsApp Messenger Smartphone Terhadap WhatsApp Berbasis Web.” Jurnal Ilmu Teknik Elektro Komputer dan Informatika JITEKI, Vol. 3, No. 1, Juni 2017

[4] A. Yudhana, et al., " Akuisisi Data Forensik Google Drive Pada Android Dengan Metode National Institute of Justice (NIJ)” Jurnal CoreIT, Vol.4, No.1, 2018

[5] I. Riadi, R. Umar, I.M. Nasrulloh., " Analisis Forensik Digital Pada Frozen Solid State Drive Dengan Metode National Institute Of Justice (NIJ)" ELINVO (Electronics, Informatics, and Vocational Education), pp70-82 May 2018.

[6] A. Yudhana, I. Riadi, I. Zuhriyanto., “ Analisis Live Forensics Aplikasi Media Sosial Pada Browser Menggunakan Metode Digital Forensics Research Workshop (DFRWS)," in TECHNO, Hal. 125 130 Vol.20, No.2, Oktober 2019.

[7] R. Bintang, R. Umar, A. Yudhana., "Perancangan Perbandingan Live Forensics Pada Keamanan Media Sosial Instagram, Facebook Dan Twitter Di Windows 10," in UNWAHAS Semarang pp.125-128, Vol 1, No 12018

[8] W. Ari Mukti, et al., " Analisa Dan Perbandingan Bukti Forensik Aplikasi Media Sosial Facebook Dan Twitter Pada Smartphone Android," JURNAL TEKNIK INFORMATIKA VOL. 10 NO. 1, 2017.

[9] I. Riadi, A. Fadlil, A. Fauzan, l., "Evidence Gathering and Identification of LINE Messenger on Android Device," International Journal of Computer Science and Information Security (IJCSIS) Vol. 16, No. 5, 2018.

[10] R. Anggara, A. Fadlil, I.Riadi., "Forensik Mobile Pada Smartwatch Berbasis Android," in JURTI, pp. 41-47 Vl.1 No.1., 2017. 
